\title{
THE FUNCTIONS OF RUSSELL’S NO CLASS THEORY
}

\author{
KEVIN C. KLEMENT \\ University of Massachusetts_-Amherst
}

\begin{abstract}
Certain commentators on Russell's "no class" theory, in which apparent reference to classes or sets is eliminated using higher-order quantification, including W. V. Quine and (recently) Scott Soames, have doubted its success, noting the obscurity of Russell's understanding of so-called "propositional functions." These critics allege that realist readings of propositional functions fail to avoid commitment to classes or sets (or something equally problematic), and that nominalist readings fail to meet the demands placed on classes by mathematics. I show that Russell did thoroughly explore these issues, and had good reasons for rejecting accounts of propositional functions as extralinguistic entities. I argue in favor of a reading taking propositional functions to be nothing over and above open formulas which addresses many such worries, and in particular, does not interpret Russell as reducing classes to language.
\end{abstract}

§1. Introduction. Although Whitehead and Russell's Principia Mathematica (hereafter, $P M$ ), published almost precisely a century ago, is widely heralded as a watershed moment in the history of mathematical logic, in many ways it is still not well understood. Complaints abound to the effect that the presentation is imprecise and obscure, especially with regard to the precise details of the ramified theory of types, and the philosophical explanation and motivation underlying it, all of which was primarily Russell's responsibility. This has had a large negative impact in particular on the assessment of the socalled "no class" theory of classes endorsed in PM. According to that theory, apparent reference to classes is to be eliminated, contextually, by means of higher-order "propositional function"- - variables and quantifiers. This could only be seen as a move in the right direction if "propositional functions," and/or higher-order quantification generally, were less metaphysically problematic or obscure than classes themselves. But this is not the case-or so goes the usual criticism.

Years ago, Geach (1972, p. 272) called Russell's notion of a propositional function "hopelessly confused and inconsistent." Cartwright (2005, p. 915) has recently agreed, adding "attempts to say what exactly a Russellian propositional function is, or is supposed to be, are bound to end in frustration." Soames (2008) claims that "propositional functions ... are more taken for granted by Russell than seriously investigated" (p. 217), and uses the obscurity surrounding them as partial justification for ignoring the no class theory in a popular treatment of Russell's work (Soames, 2003). ${ }^{1}$

A large part of the usual critique involves charging Russell with confusion, or at least obscurity, with regard to what a propositional function is supposed to be. Often the worry has to do with the use/mention distinction: is a propositional function, or even a proposition,

Received: October 9, 2009

1 For criticisms of this decision, see Kremer (2006); Pincock (2006); Proops (2006); Sainsbury (2006), and for follow-up discussion see Soames (2006); Kremer (2008); Soames (2008). 
in the vocabulary of $P M$, a piece of language, or some extralinguistic abstract entity corresponding to one? This tradition of criticism goes back all the way to Frege (1980, pp. 8184), and includes such notables as Quine (1981, 1995), Church (1976, p. 748n), and Gödel (1944, pp. 147-49).

Another part of the critique often takes the form of claiming that even once such ambiguities are removed, we must understand propositional functions in a way that undermines any advantage their use would have over the use of classes instead. In other words, whatever a propositional function could be, it is either the sort of thing we need classes, realistically understood, to make sense of, or, the sort that on its own gives rise to all the same kinds of problems and worries that classes themselves do, if not more. Quine writes:

Russell ... had a no-class theory. Notations purporting to refer to classes were so defined, in context, that all such references would disappear on expansion. This result was hailed by some ... as freeing mathematics from platonism, as reconciling mathematics with an exclusively concrete ontology. But this interpretation is wrong. Russell's method eliminates classes, but only by appeal to another realm of equally abstract or universal entities-so-called propositional functions. The phrase 'propositional function' is used ambiguously in Principia Mathematica; sometimes it means an open sentence, and sometimes it means an attribute. ... Such reduction comes to seem pretty idle when we reflect that the underlying theory of attributes itself might better have been interpreted as a theory of classes all along .... (Quine, 1980, pp. 122-23)

Compare a more recent criticism from Soames (2008, p. 217):

[Russell] speaks confusingly and inconsistently about [propositional functions], and the view that seems to be uppermost in his mind-that they are expressions - is obviously inadequate. Although other choicesextensional $_{1}$ functions and gappy propositions-make more sense, he doesn't systematically explore them, and ... they aren't promising candidates for achieving ontological economies anyway.

In what follows, I take up such worries, devoting a fair bit of discussion to Soames's concerns in particular, since they were more recently articulated, and I think, exemplify widespread attitudes among contemporary working philosophers. Overall, I believe such negative assessments are emblematic of a longstanding and widespread failure to understand Russell's views. Unfortunately, Russell himself is not blameless when it comes to the prevalent misunderstandings. His frequent changes of mind, and his rather imprecise and sloppy way of expressing himself, especially when it comes to use and mention, have frustrated many readers, both contemporaneous and contemporary. Nevertheless, we are in a much better position than the previous generation to understand Russell's views, because his working manuscripts from 1902-1910 - the years in between his completion of The Principles of Mathematics and $P M$ - are now available. They leave absolutely no doubt that Russell had in fact engaged in a "serious investigation" into the nature of propositional functions, and their relationship to discourse apparently about classes; indeed, I doubt anyone since has struggled with these matters more intensely.

The development of his views during these years is fascinating, and unfortunately, we cannot even begin to scratch the surface of it here. This material, and the light it sheds on published works such as $P M$, go quite a long way toward revealing that the most 
common misgivings about Russell's no class theory simply rest on misunderstandings. Russell's views certainly weren't the incoherent mess they are often taken to be. Whether or not it would be seen as attractive by contemporary theorists working on these issues, Russell had his own understanding of how it is that his no class theory escaped some of the worries about a realistic doctrine of classes without presupposing another realm of equally problematic entities.

Russell explicitly, carefully, and thoroughly considered a variety of both realist and nominalist accounts of the nature of propositional functions at some length. By the time of 1910's PM, it is clear that Russell no longer believed in classes, propositions, or propositional functions as extralinguistic entities. In the terminology of $P M$, a propositional function is nothing but an open sentence. However, I shall argue that when the intended semantics for the higher-order quantifiers and variables of $P M$ is properly understood, most of the commonly given objections to a nominalist account of propositional functions are not clearly relevant to it, at least not without substantial qualification. However, I should be clear that my primary aim in what follows is to clarify Russell's position, not to defend or endorse it. I do think there may be difficulties with Russell's no class theory, but if so, they are not the rather blatant and crippling problems alleged by Quine, Soames, and others, but more subtle. I also aim to underscore the importance of Russell's no class theory in the greater context of his philosophy, particularly with regard to his solutions to the various forms of Russell's paradox, and his logical atomism.

\$2. The contextual definition of classes. The notion of a "class" utilized by Russell is a descendant of the notion of class that appeared in the earlier Boolean (or more specifically to Russell, Whitehead, 1898) logical tradition, in which classes were thought to be involved in all categorical judgments. When, early on, he believed in classes as things, he took them to be the objects denoted by such phrases as "all planets", etc. (Russell, 1903f, p. 67), and even later on he describes the topic of classes as the same as the topic of the word "the" used in the plural (Russell, 1919a, p. 181; for discussion, see Bostock, 2008). These days, set theory is sometimes thought of as a study of certain kinds of iterative mathematical structures, the application of which to everyday discourse is indirect at best. Russell, however, thought of discourse about classes as being ubiquitous, and took giving an account of them to be part and parcel of the core of logical theory. Early Russell understood by a "class" the extension of a concept, or what we're talking about when we make a claim about those things, all of which share a common property, where the truth of the claim depends only on the makeup of that collection. When Russell became convinced that his initial naïve view of classes could not be right, what he sought was a new understanding of what it is we're doing when we make a claim about "the such-andsuches," where the claim made is extensional, that is, depends for its truth or falsity only on the extension of the such-and-suches, and not on how they are described.

According to Russell's mature no class theory, what appears as a term for class should not be understood as an independently meaningful component of a sentence. Instead, these apparent terms are "incomplete symbols," making a contribution to the meaning of sentences wherein they appear in a more complicated way. This theory has many things in common with his well-known theory of descriptions, according to which phrases of the form "the $\phi$ ", or " $(1 x) \phi x$ ", although not definable on their own, instead can be defined in context; in particular ( $P M$ p. 68):

$$
f\{(\iota x)(\phi x)\} .=:(\exists c): \phi x . \equiv_{x}, x=c: f c \quad \text { Df. }
$$


Or in more modern notation:

$$
A((1 x) \phi x)=\mathrm{df} \exists y[\forall x(\phi x \leftrightarrow x=y) \wedge A(y)]
$$

This does not define " $(1 x) \phi x$ " outright, but instead provides a way of transcribing an entire sentential context in which a phrase of this form appears into another in which it does not. Similarly, Russell does not define a class abstract " $\hat{z} \psi z$ " outright, but instead offers the following contextual definition in $P M$ :

$$
f(\hat{z} \psi z) \cdot=:(\exists \phi): \phi ! x . \equiv_{x} \cdot \psi x: f(\phi ! \hat{z}) \quad \text { Df. }
$$

Modernizing:

$$
A(\{z \mid \psi z\})=\mathrm{df} \exists F[\forall x(F ! x \leftrightarrow \psi x) \wedge A(F ! \hat{z})]
$$

Speaking very loosely, we may read this as saying that some claim, $A$, made about the class of $z$ such that $\psi z$, can be rephrased by saying that there is some $F$ (a predicative propositional function), such that $F$ holds of all and only those $x$ such that $\psi x$, and $A$ can be claimed of $F$. To give a concrete example, given Russell's simple definition of the membership sign (whereupon " $x \in \phi \hat{y}$ " is a long form of " $\phi x$ "), the claim that "Socrates is a member of the class of humans," or "Socrates $\in\{z \mid z$ is human $\}$ " is to be analyzed as:

$$
\exists F[\forall x(F ! x \leftrightarrow x \text { is human }) \wedge F \text { !(Socrates) }]
$$

That is, for some $F, F$ holds of all and only humans, and $F$ holds of Socrates.

Like the contextual definition of descriptive phrases, this analysis creates scope ambiguities when a sentential context containing an apparent class term is part of a larger sentential context. For example, " $\sim($ Socrates $\in\{z \mid z$ is human $\})$ " is ambiguous between (2) and (3):

$$
\begin{aligned}
& \exists F[\forall x(F ! x \leftrightarrow x \text { is human }) \wedge \sim F ! \text { (Socrates) }] \\
& \sim \exists F[\forall x(F ! x \leftrightarrow x \text { is human }) \wedge F !(\text { Socrates })]
\end{aligned}
$$

In (2) the contextual definition is applied to the entire larger sentential context, and in (3) it is applied only inside the scope of the negation. If, as in (2), it is applied to the entire sentence, the class term is said to have primary occurrence; otherwise, it is said to have secondary occurrence. In this particular case, provided that there is a predicative propositional function satisfied by all and only humans ${ }^{2}$ the two formulations are equivalent. They need not be equivalent if an intensional context is involved. The reason that "Socrates is a member of the class of humans," is not rendered more simply as "Socrates is human", is that Russell wanted the general definition, applicable to various sorts of statements, to capture the extensional nature of class talk. That is, he wanted to ensure that a sentence containing a class term " $\{z \mid \psi z\}$ " given primary occurrence would always have the same truth value as the corresponding statement about " $\{z \mid \varphi z\}$ " (again given primary occurrence) if $\psi$ and $\varphi$ are coextensive.

One important difference between this contextual definition and Russell's contextual definition of descriptive phrases, recently stressed by Kremer (2008, p. 211), is that (Elim) is compatible with the complete elimination of classes from the ontology. While, in the case of descriptions, Russell does not analyze a statement involving "( $1 x) \phi x$ " as naming or referring to the unique individual satisfying $\phi x$ (even when there is such), in order for

2 The Axiom of Reducibility ensures that for every open sentence, there is an equivalent predicative propositional function. 
a statement in which " $(1 x) \phi x$ " appears (with primary scope) to be true, there still must be, in the range of the quantifiers, some such individual. On the other hand, at least prima facie, (Elim) removes the need for classes to exist at all in the range of any quantifiers in order for a statement involving " $\{z \mid \psi z\}$ " to come out as true (whatever the occurrence). Instead of quantification over classes, the analysis utilizes higher-order quantifiers of the form " $\forall F$ " and " $\exists F$ ". Russell speaks of these as (predicative) "propositional function" variables; later commentators use the phrase "predicate variables," though I think it best to avoid this particular phrase. ${ }^{3}$

Russell himself describes what is achieved by this contextual definition differently in different places. Normally, when a philosopher claims that discourse about $X$ 's can be defined in terms of $Y$ 's, he or she is not denying the existence of $X$ 's, but simply claiming that their existence reduces to that of other things. Indeed, Russell often allows himself to speak about classes realistically, as if, there are classes all right, only they are not fundamental or logically or metaphysically primitive - to say that they exist is to say something of a different sort than a usual existence claim, but is nonetheless true (Russell, 1918 b, p. 260ff). However, the very label of "no class theory," his frequent description of classes as "fictions," and his admissions that he cannot understand how type restrictions would hold for classes "if there were such things as classes" (Russell, 1910b, p. 376; quoted at length below), make it sound as if he were disavowing the existence of classes (Russell, 1914, pp. 160-01, 1919a, pp. 14, 137). Still elsewhere he claims a kind of agnosticism according to which he is neither positively claiming that classes exist, nor denying it (Russell, 1919a, p. 184; Whitehead \& Russell, 1910, p. 24).

The truth seems to be that Russell, as an ideal language philosopher, was not attempting in any way to give an account of the meaning of our actual class talk. He is aware that our ordinary way of speaking of classes make terms for classes appear as terms for individuals. Russell believes that it is problematic to hold a view according to which that kind of talk can be taken at face value, and as metaphysically loaded: it leads to paradoxes such as the one bearing his name. What he is offering is not an analysis of such talk, but a replacement for it aimed at those interested in the foundations of mathematics. The replacement does not positively assert that there aren't individuals that have the characteristics we ordinarily assume classes have. However, what makes the replacement desirable is precisely that it does not have the same kinds of problems our ordinary discourse has when treated at face value. Nevertheless, the replacement preserves enough of the formal features of class talk to make it suitable for the development of mathematics (and perhaps other technical disciplines which invoke classes) without much distortion. (See, e.g., Russell, 1908, pp. 81-82, 1924, p. 327; Whitehead \& Russell, 1910, pp. 72, 166.) Insofar as our best scientific theory can be taken as a reliable guide to the way the world is, not the no class theory itself, but reflection on its success as a replacement for ordinary discourse, reveals that there aren't, among the building blocks of reality, things deserving the name "class." The contextual definition of classes legitimizes discourse that appears to be about classes, but since the definitions are contextual, there is nothing in reality in particular with which classes are "reduced" or defined as being (Russell, 1919a, p. 184). Classes are not

3 Russell uses the word "predicate" in a different, and incompatible, way. For example, he writes, "predicates are only some among what we have called 'predicative functions"" (Russell, 1919a, p. 192), and in the second edition of $P M$ (p. xxxii), speaks of the possibility, not acted upon, of utilizing "variable predicates," and it's clear from the discussion that he would regard this notation as distinct from that of propositional function variables. For general discussion of the difference, see Linsky (1988); Klement (2004, 2005). 
identified with propositional functions, it's just that the reality underlying class talk on the new construal, is the same as that underlying higher-order quantified propositions.

Even considered only as a substitute for our ordinary discourse about classes, rather than an interpretive analysis, however, one might share Soames and Quine's worry that the appearance of ontological economy may be illusory if, in order to make sense of quantification using propositional function variables, we must still in the end posit classes or similar entities. So-called "standard" interpretations of second-order variables take their values simply to be sets or classes. Clearly, this could not have been what Russell had in mind. Nevertheless, the issue is still unsettled until we know how Russell would understand the semantics of these variables and quantifiers. This issue is of course related to (though, I think not quite identical to) the broader question as to what Russell takes a "propositional function" to be. As we have seen, many commentators find Russell to be obscure on this point, and even contemporary scholars disagree.

Addressing these concerns of course requires providing Russell with a theory of the nature of propositional functions, or at least of higher-order quantification, that does not circularly bring in commitment to classes at another level. Interpretations can be divided into two broad categories, roughly going hand in hand with the two uses with which he is charged with ambiguously using the phrase: realist accounts, according to which propositional functions are taken as extralinguistic abstract entities of some sort or another, and nominalist accounts, according to which propositional functions are simply taken as expressions of a certain kind. It is worth considering them in turn.

§3. Realist accounts of propositional functions. Both Quine and Soames-although admitting that Russell sometimes uses the phrase "propositional function" to mean an open sentence-seem to think that the most faithful (or, perhaps, charitable) understanding of Russell's logic would take propositional function variables to involve quantification over abstract entities of some sort: complex attributes, gappy propositions, or something similar. Soames discusses two possible realist or nonlinguistic understandings of propositional functions that might be adopted, but concludes that neither escapes a more general commitment to classes. The first, outlined already in (Soames, 2003, chap. 5), depicts a propositional function as a mapping from arguments to structured propositions as values:

We let ' $x$ is green' denote the propositional function $g$, which assigns to any object $o$ the proposition expressed by ' $x$ is green' relative to an assignment of $o$ to ' $x$ '. This proposition is a structured complex in which the property of being green is predicated of $o$. (Soames, 2008, p. 214)

Here, the propositional function represented by " $x$ is green", could be understood as a function taking Socrates to the structured proposition Socrates is green, and Kermit to the proposition Kermit is green, and so on. Soames points out that there is no objection to identifying such mappings when they take the same objects to the same propositions, since even though they are then "extensional [1]" in one sense, the view does not identify propositional functions which are satisfied by all and only the same arguments (where satisfaction is simply being mapped to some true proposition by the function). ${ }^{4}$

4 This is in response to Kremer's (2008, p. 211n) insistence that propositional functions must be intensional entities. I think Soames's response is successful against this criticism, though of course that does not validate Soames's reading. 
One natural way of understanding such "mappings" or "functions" is that they are set theoretic entities, for example, sets of ordered pairs consisting of arguments and resulting propositions. This is the way Soames defines them in his Soames (2003). Of course, then, there is no escape from ontological commitment to sets or classes. In follow-up discussion, Soames insists however, that it is not crucial to understand them this way. His complaint is, rather, that if functions or mappings of this sort, with propositions as value, are recognized in Russell's ontology, "one can hardly refuse to recognize similar functions from objects to other entities, including truth values." (Soames, 2008, p. 215). Since a function from objects to truth values can, for all formal intents and purposes, be identified with a class, this view does not escape commitment to entities on par with classes.

Soames is right that if this were Russell's understanding of propositional functions, his so-called "elimination of classes" would be a failure. Happily, there is ample evidence that this was not, and could not have been, his view. By the time of $P M$, of course, Russell had already abandoned structured propositions, as extralinguistic entities, from his ontology (Russell, 1910a; Whitehead \& Russell, 1910), so certainly he could not have then accepted an account of propositional functions that presupposed them. However, even in the earlier period when he did believe in such propositions, he explicitly considered and rejected views similar to this. For example, in Russell (1903f, p. 509), he considers a view that defines a propositional function as "a many-one relation which has all terms for the class of its referents, and has its relata contained among propositions." (There is little reason to differentiate a function in Soames's sense from a many-one relation.) He follows this up with the remark that "the air of formal definition [here] ... is fallacious, since propositional functions are presupposed in defining the class of referents and relata of a relation," clearly aware that such a view is in danger of leading to a circularity between the definitions of classes and propositional functions. ${ }^{5}$ Despite some vacillation on the subject in the meantime (see especially Russell, 1903c, p. 339ff), by 1904 he came to the conclusion that other sorts of functions are to be taken as derived from propositional functions, and not vice-versa (e.g., Grattan-Guinness, 1977, p. 79; Russell, 1903c, p. 332), and hence that propositional functions cannot simply be understood as a species of functions in a more general sense, something echoed in later writings (see, e.g., Whitehead \& Russell, 1910, p. 15; Russell, 1919a, p. 46; and 1958, pp. 92-93). In $P M(* 30)$, other sorts of functions, which he called "descriptive functions," were analyzed in terms of his theory of descriptions along with his theory of relations-in-extension, which were themselves understood as "logical fictions," on par with classes, receiving an eliminative contextual definition much like $* 20.01$, except by means of propositional functions with two variables or two arguments rather than one $(* 21)$.

The other realist account considered by Soames identifies propositional functions with "propositional matrices," that is, "propositions with gaps in them," a reading perhaps suggested by the common identification of propositional functions with complex or compound properties. Although Soames does not think this conception of propositional functions is flawed in itself, he again questions whether it escapes commitment to classes, adding:

For what is a propositional matrix? It would seem, at the very least, to be a kind of sequence (with gaps) the elements of which are either individual meanings or sequences of meanings. But now we are back to

5 Russell's much later skepticism about Ramsey's "propositional functions in extension" can also be read as a rejection of this sort of account; see Russell (1932, 1958, pp. 92-93). 
an earlier objection. For what are sequences, if not set theoretic constructions, or something so similar as to be ontologically on a par with sets? (Soames, 2008, pp. 216-17)

Soames evidently has in mind a view of structured propositions understood as sequences of parts, which might simply be (as in many contemporary philosophy of language discussions $^{6}$ ) identified with ordered sets. The proposition expressed by "Callisto orbits Jupiter" could be taken to be 〈Orbiting, Callisto, Jupiter〉. Then a propositional function is taken as some such structure with a gap or spot to be filled, for example, " $x$ orbits Jupiter", might be taken as representing 〈Orbiting, Jupiter $\rangle$. I doubt Soames would insist upon this particular understanding of ordered propositions or sequences, but he seems to think that any other analysis will bring in set theoretic entities at some point, or entities (generic functions, abstract tree-like structures, etc.) so similar that, again, no ontological parsimony results.

While with the earlier interpretation, I found Soames's claim that the view cannot escape commitment to classes, or something similar, plausible, here I think he goes too fast. It is tantamount to the suggestion that the structure of structured propositions must be understood in a set theoretic way. During the period in which Russell (1903f) did believe in extralinguistic structured propositions, he described a proposition as a "unity," more than simply the sum of its parts; and indeed, explicitly differentiated the kind of complexity involved with such unities with the kind of complexity involved with sets or classes $(§ 135)$. The unity of the proposition Callisto orbits Jupiter is provided by the relation of Orbiting occurring in this proposition in a relating way, that is, as relating Callisto to Jupiter. It provides the "metaphysical glue," as it were, holding the entire proposition together. Here it must be remembered that a proposition for early Russell (1904b, pp. 473-474, 1905a, pp. 492-495) is not itself a meaning or representation, something made true by something else, but is itself understood as a state of affairs. Indeed, early Russell identified facts with true propositions. It is at least arguable that this kind of structure-the forms of states-ofaffairs or facts-is more basic than anything set theoretic. Someone sympathetic with the kinds of metaphysics suggested by this picture would likely claim that insofar as sets can model structures at all, they can do so only because of facts about the membership relation bearing this more fundamental kind of structure. ${ }^{7}$

Other interpreters of Russell seem to understand propositional functions as much like structured propositions, except incomplete or gappy, but where this kind of structure is understood non-set-theoretically. For example, Kremer (2008, p. 211n) writes:

For Russell: (a) propositional functions are real, non-linguistic entities;

(b) that propositions are analyzable into function and argument is required to account for the unity of the proposition .... .

The view hinted at is reminiscent of Frege's account of the unity of judgments or thoughts, whereupon the meanings of certain function expressions are thought of as "incomplete," or "unsaturated," and the unity of the judgment or thought is brought about by the removal

6 Unfortunately, propositions understood this way are often there called "Russellian propositions," misleadingly.

7 Soames expresses doubts about Russell's views about the unity of propositions in (Soames, forthcoming). I think his worries are partly based on misreading Russell as having had a representational account of propositions, but we cannot address this issue in full here. 
of this incompleteness through saturation by an argument. ${ }^{8}$ Kremer, or someone else with a related view, might similarly suggest that the unity of a Russellian proposition is provided by an incomplete or gappy thing - a propositional function-being completed by an argument to form a whole.

Again, however, there is evidence that Russell did not hold such a view of propositional functions, even before he abandoned structured propositions (without which, of course, this sort of view makes little sense). Indeed, he explicitly rejected the Fregean view of functions. First, he claims that the Fregean view cannot explain the identity function or differentiate the differing argument spots of a multi-argument function:

Frege's general definition of a function, which is intended to cover also functions which are not propositional, may be shown inadequate by considering what may be called the identical function, i.e., $x$ as a function of $x$. If we follow Frege's advice, and remove $x$ in hopes of having the function left, we find that nothing is left at all; yet nothing is not the meaning of the identical function. Frege wishes to have the empty places where the argument is to be inserted indicated in some way; thus he says that in $2 x^{3}+x$ the function is 2()$^{3}+()$. But here his requirement that the two empty places are to be filled by the same letter cannot be indicated: there is no way of distinguishing what we mean from the function involved in $2 x^{3}+y$. (Russell, 1903f, §482)

The worry about the identity function might not carry over if the analysis were to be restricted to propositional functions, but the second worry would remain: one needs to distinguish the functions represented by " $x=x$ " and " $x=y$ ", and it is unclear how to do so on this view unless different gaps can be differentiated somehow.

In making this criticism of Frege, Russell is harkening back to his own discussion in chap. VII of Russell (1903f), in which he discusses whether what he there calls "assertions," can be made to do the logical work of propositional functions, where an "assertion" can be defined as "everything that remains of a proposition when the subject is omitted" $(\S 81) .{ }^{9}$ He argues that, in attempting to do so, we lose the ability to differentiate between the meanings of " $x$ is a man implies $x$ is a mortal", and " $x$ is a man implies $y$ is a mortal", and generally, the difference between $x R y, y R x$, and $x R x$ ( $\$ 82)$. Indeed, he goes on to argue that in most cases, there can be no entity obtained by simply removing a constituent from a proposition. In many ways, this is demanded by what Russell did believe provided the unity of propositions or facts: simple relations (universals) occuring in a relating way. ${ }^{10}$

8 See, for example, Frege (1984). Frege sometimes calls the reference (Bedeutung) of a function expression, that is, the function itself, unsaturated or incomplete, and sometimes the sense (Sinn), and sometimes both. In the case of the reference, however, it is not entirely clear what the resulting unity would be, since the value of a function does not seem to be composed of the function and argument. For further discussion, see Klement (2002, chap. 5, 2004).

9 Notice also that Russell (1903f) explicitly identifies Frege's Begriffe-the functions represented by predicates according to Frege_as "very near" his notion of "assertion" (\$480) and hence concludes that "what Frege calls a function ... is in general a non-entity" (\$482).

10 See, for example, Russell (1910b, 1931). There is unfortunately, still a tendency to think that Russell identified simple relations in intension, including monadic relations (which he called predicates, concepts, or universals), with a kind of propositional function. I have argued against this misreading elsewhere (Klement, 2005, 2004), and see also Note 3. 
It is unclear how Orbiting could occur as a relating relation in is nothing in it for it to relate to Jupiter. ${ }^{11}$ Russell concludes:

orbits Jupiter if there

... in general it is impossible to define or isolate the constant element in a propositional function, since what remains, when a certain term, wherever it occurs, is left out of a proposition, is in general no discoverable kind of entity. (Russell, 1903f, §107)

Finally, another reason Russell comes to the conclusion that "the $\phi$ in $\phi x$ is not a separable and distinguishable entity" is that, rejecting the Fregean view that there are things that are not capable of being logical subjects, the opposite view leads to the supposition that there is such an "assertion" as is not assertible of itself, and if this assertion completes its own gap, a contradictory proposition results. ${ }^{12}$

§4. Russell's retreat from a realist view. While Russell toyed with a variety of realist views of propositional functions between 1902 and 1905, more and more his views pushed him in a way that made it impossible to accept any kind of account of propositional functions as extralinguistic entities. His primary intellectual preoccupation during this period was the attempt to solve the logical paradoxes hampering his work in the foundations of mathematics. This was a time of great intellectual experimentation for Russell, and it would take a book-length treatment to chart the twists and turns of his thought. We can give only a rough outline here. In 1906, he described the evolution of his views up until then in a letter to Phillip Jourdain thusly:

I am not sure that I can remember how my ideas developed. But I will tell you all I can. ... My book [i.e., Russell, 1903f] gives you all my ideas down to the end of $1902 \ldots$. Then in May 1903, I thought I had solved the whole thing by denying classes altogether. I still kept propositional functions ... . I treated $\phi$ as an entity. All went well till I came to consider the function $W$, where

$$
W(\phi) . \equiv . \sim \phi(\phi)
$$

This brought back the contradiction, and showed that I had gained nothing by rejecting classes.

... Then in April 1904 I began working at the Contradiction again, and continued at it, with few intermissions, till January 1905. I was throughout much occupied by the question of Denoting, which I thought was probably relevant, as it proved to be. ... Gradually I discovered that to assume a separable $\phi$ in $\phi x$ is just the same, essentially, as to assume a class defined by $\phi x$, and that non-predicative functions must not be analyzable into $\phi$ and an $x$.

11 This complaint is not altogether unlike complaints lodged against set theoretic conceptions of gappy propositions that point out that there can be no such thing as an ordered $n$-tuple where one of the $n$ things is missing, at least according to most set theories. And notice that here the problem is worse, since one cannot appeal to the usual maneuver of substituting a dummy place-holder object in the gap if one is to invoke these entities to account for the unity of a proposition, since such a complex would have already to possess the kind of unity in question.

12 See Russell (1903f, §85). This passage is often misunderstood; I try to clear things up in Klement (2005). 
About June 1904, I tried hard to construct a substitutional theory more or less like my present theory. But I failed for want of the theory of denoting: also I did not distinguish between substitution of a constant for a constant and determination of a variable as this or that constant ...

Then, last autumn, as a consequence of the new theory of denoting, I found at last that substitution would work, and all went swimmingly. (Grattan-Guinness, 1977, pp. 78-80)

This letter and Russell's manuscripts of the period show that he was fully aware that it is no genuine achievement simply to reject classes as entities as a "solution" to Russell's paradox (or others) if the entities used to replace them in his formal work are no less problematic. It also shows, albeit more indirectly, another aspect of Russell's views which is still too often missed. He insisted that if propositional functions are thought of as "entities," things that can be seen as "separable" from their values, then it must be possible for them to occur in the subject position in propositions, and even as possible arguments to themselves. This is in keeping with his insistence, that (propositional) functions must be objects if they are anything at all, as Russell wrote when complaining to Frege about his distinction between functions and objects:

If there can be something which is not an object, then this fact cannot be stated without contradiction; for in the statement, the something in question becomes an object. (Frege, 1980, p. 134; cf., Russell, 1903f, $\S \S 47,481$; Linsky, 2004, p. 17)

Although it is often thought that Russell changed his mind about this when adopting the theory of types of $P M$, recent research has instead shown that Russell was driven to his views in $P M$ largely by his attempt to preserve this doctrine as best as possible. ${ }^{13}$

During the period in which Russell did regard propositional functions as extralinguistic entities, his understanding of them was bound up with his theory of denoting concepts from Russell (1903f, chap. 5). He followed his remark (quoted earlier) that "what remains, when a certain term ... is left out of a proposition, is in general no discoverable kind of entity" with the suggestion that "the term in question must be not simply omitted, but replaced by a variable" (\$106). During most of this period, Russell understood a variable, either, as in Russell (1903f, chap. 8), as a special kind of entity denoted by certain kinds of denoting concepts, or, later on, as an entity that itself denotes its possible values (rather than as anything linguistic). In 1903-1904, Russell (1903a, 1903c, 1903e, 1904d) seems to have understood a propositional function as a kind of proposition-like complex except containing a variable instead of an ordinary entity in one or more of its places, and can thereby be understood as a "dependent variable," or denoting complex that denotes different propositions depending on what value is denoted by the variable. Russell used various notations throughout this period for speaking of a propositional function itself as opposed to one of its values (see Klement, 2003), eventually settling on the circumflex notation familiar to readers of $P M$. Russell believed that to use this notation is in effect to speak of a denoting complex as opposed to its denotation, writing:

The circumflex has the same sort of effect as inverted commas have. E.g., we say

13 See especially Klement (2004); Landini (1998); Stevens (2005). 
Any man is a biped;

"Any man" is a denoting concept.

The difference between $p \supset q . \supset . q$ and $\hat{p} \supset \hat{q} . \supset . \hat{q}$ corresponds to the difference between any man and "any man". (Russell, 1904a, pp. 12829)

Since formulating the version of Russell's paradox involving the propositional function satisfied precisely by those propositional functions that do not satisfy themselves requires being able to speak of a propositional function itself as opposed to its values, we here have one obvious explanation of why Russell's work on paradox solving brought him to explore the nature of denoting in general, and the possibility of differentiating truths involving denoting complexes from truths involving their denotations in particular.

While Russell's (1903b, 1903c, 1903d, 1904e) views changed often during this period, and contrary understandings were considered, for the most part he gravitated to a view according to which the relationship between a propositional function and its values is strictly that of denoting object to object denoted, and not that of incomplete part to whole (Russell, 1904a, 1904c, 1905d). If anything then, a propositional function is something abstracted from the general form of its values, and logically posterior to those values, and a fortiori, not something responsible for providing their unity. As Russell (1904a) wrote, "There is no $\phi^{\prime} \hat{x}$ presupposed by $\phi^{\prime} x$ " (p. 118), a view echoed in PM itself (pp. 39, 55). Given that he then understood propositional functions themselves as a kind of unity bearing almost precisely the same structures as their values, only with variables in place of definite objects, the contrary view would simply lead to a regress. Indeed, he had hoped that the propositional functions version of the paradox, and perhaps others, could be solved by insisting that it is sometimes a mistake to attempt to abstract such a function as a distinct entity even from a group of values that seemed to share a common form. He wrote, "I think it is fairly certain that the root of the Contradiction is the fact that $\phi^{\prime} \hat{x}$ is not a constituent of $\phi$ ' $x$ " (Russell, 1904a, p. 154), and sought to explore under which conditions propositional functions do and do not exist as separate entities.

In the letter to Jourdain quoted earlier, Russell alludes to an early "substitutional theory," beginning in 1904. This involves the way in which he at the time sought to represent the value of a given propositional function for a given argument. Since a propositional function, say $\hat{x}=\hat{x}$, was thought of as a proposition-like unity containing a variable in place of a definite object, its value for a given argument $a$, might be thought of as what results when $a$ is substituted for the variable. Russell wrote this as " $(\hat{x}=\hat{x}) \frac{a}{\hat{x}}$ ", or, more generally, in a schematic form " $C \frac{a}{\mathrm{Var}}$ " with " $C$ " replaced by the name of a complex, "Var" by any name of a variable, and " $a$ " by any term (see, e.g., Russell, 1904a, p. 129ff, 1905b, p. $275 \mathrm{ff}, 1905 \mathrm{~d}$, p. $361 \mathrm{ff}$ ). This way of treating things relies on Russell's older theory of denoting in at least two ways. The first lies in its understanding of what variables are generally, and how they work. The second is that an expression like " $(\hat{x}=\hat{x}) \frac{a}{\hat{x}}$ " must itself be understood as meaning another kind of denoting complex, since it would seem to represent the same proposition as " $(\hat{x}=a) \frac{a}{\hat{x}}$ " or " $(a=\hat{x}) \frac{a}{\hat{x}}$ ", or just " $a=a$ ", yet there is a cognitive difference between them. In particular, when embedded within a larger sentence, if any of the first three are used, the proposition expressed would seem to be not only about this proposition, but also about a propositional function named by the circumflex abstract, but not so if " $a=a$ " is used instead. These expressions therefore must mean different things even if they have the same denotation.

Famously, in mid-1905, Russell (1905c) came finally to reject his old theory of denoting concepts/complexes, giving an argument to the effect that any attempt to differentiate 
truths about denoting entities themselves as opposed to what they denote must fail. ${ }^{14}$ Unsurprisingly, then, in the same year he adopted a different understanding of substitutions. In " $(\hat{x}=\hat{x}) \frac{a}{\hat{x}}$ ", the letter " $x$ " is not used as a "real" (i.e., free) variable, but always with a circumflex, and in effect, one can understand " $\hat{x}$ " as if it were a constant for a specific placeholder object. Russell realized that there is no reason to insist on utilizing a variable there rather than just any definite object, and instead began to use such constructions as " $(b=b) \frac{a}{b}$ ", with both " $a$ " and " $b$ " used as constants. Hence, " $b=b$ " here stands for a definite proposition rather than a function or "dependent variable." Russell now suggests that what should be taken as primitive is a four-place relation, written " $p \frac{x}{y} ! q$ " which means that $q$ results from the substitution of $x$ for $y$ wherever it occurs in $p$. The simpler notation " $p \frac{x}{y}$ " is shorthand for the description, " $(1 q)\left(p \frac{x}{y} ! q\right)$ ", where this in turn would be treated according to his new contextual definition of descriptions (given in Section 2 above). Russell is then able to explain the cognitive differences between " $(b=b) \frac{a}{b}$ ", " $(a=b) \frac{a}{b} ", "(b=a) \frac{a}{b} "$, and " $a=a$ " in a manner entirely analogous to his explanation of the difference between "the author of Waverly" and "Scott".

All the work previously assigned to the entity $\hat{x}=\hat{x}$ he realizes now can be assigned to what he calls a "matrix," which is not a single entity, but two entities, and in this case the proposition $b=b$ and $b$. Quantification over functions is no longer necessary, and one can quantify over two entities: a proposition and an entity to be substituted for in that proposition. Rather than writing, for example, “ $(\phi)(\phi a \supset \phi b)$ ”, Russell can instead write, " $(p)(x)\left(p \frac{a}{x} \supset p \frac{b}{x}\right)$ ". The formal properties of the system are very similar to a simple type theory, in that, while statements which on some description might be said to be "about" matrices are possible, there is no way to represent a matrix taking itself as argument. ${ }^{15}$ Russell at times used the notation " $p / b$ " for the matrix consisting of $p$ and the entity in it, $b$, to be substituted for. However, this notation was only to be used as part of the fuller notation, " $p / b ; x ! q$ " - a mere notational variant of " $p \frac{x}{b} ! q$ ". There is no one thing that is the matrix; " $p / b$ " is not meaningful in isolation, and " $p \frac{p / b}{b} ! q$ " is as ungrammatical as " $(p \supset) \equiv q$ " would be. The approach does not countenance propositional functions as separable entities at all, and yet, by means of matrices, is able to do the work of a logical system that does. Moreover, through an early version of his contextual definition of classes, it was also able to do the work of a class theory, again, formally similar to one adopting the simple theory of types. It thereby blocks both Russell's class paradox and the similar one involving propositional functions, but without countenancing different logical kinds of genuine entities at all. In other words, it maintains the notion that "there is really nothing that is not an individual" (Russell, 1906a, p. 206), or as he put it elsewhere (Russell, 1906b, p. 189) "the old maxim that, 'whatever is, is one'."

Russell held a theory broadly of this form throughout most of 1906 and much of 1907 (see, e.g., Russell, 1906a, 1906b), and it even forms the official explanation of types in Russell's well-known 1908 article on type theory (1908, see esp. pp. 238-39). Unfortunately, after writing the letter to Jourdain quoted above, things did not continue to "go swimmingly."

While it provided what was, to his mind, philosophically adequate solutions to the class and function versions of Russell's paradox, he discovered that there were paradoxes

14 Unfortunately, the argument in question, the infamous "Gray's Elegy Argument," is a difficult and obscure one, and interpreting it in full and relating it to Russell's work on the paradoxes is beyond the scope of the present essay.

15 For fuller examination of its formal properties, see Landini (1998, pt. II). 
involving propositions themselves it was not similarly able to dispatch. For the most part, these were successors of the Cantorian paradox of propositions sketched already in $\$ 500$ of Russell (1903f). By Cantor's powerclass theorem, there must be more classes of propositions than propositions. The problem is that it seems possible, for each class of propositions, to generate a new proposition (such as the proposition that all propositions in it are true, etc.) Cantor's diagonalization procedure then generates a contradiction. The reasoning leading to this contradiction can be reconstructed even if classes are not thought of as genuine entities, and are proxyed by substitutional means, so long as one can always ask, for every proposition and "class" of propositions, whether or not the proposition is a member of the class. Russell modified the theory in various ways in response, including dividing propositional variables into different categories based on what their values themselves quantify over, that is, the ramified orders of propositions in Russell (1908), as well as denying the reality of quantified propositions while still admitting elementary propositions and quantified "statements" (as in Russell, 1906a; a variety of positions are considered in Russell, 1907c). In each case, he found that either the theory was too weak to be used as a foundations for mathematics, or philosophically problematic in some other way, or subject to some version of a propositional paradox. A particularly recalcitrant propositional paradox in the substitutional theory is described by Russell in a letter to Hawtrey in 1907 as having "pilled" the substitutional theory. ${ }^{16}$

The theory he moved to next can be understood as taking things further along the same trajectory. He had had success solving other versions of the paradox by holding that discourse about "classes" and "propositional functions" is not to be taken straightforwardly as about categories of logical entities of certain sorts. He seems to have drawn the lesson that if reifying apparent "entities" of a certain kind leads to a logical paradox, this is an indication that the "entities" in question must not be genuine, but façons de parler. ${ }^{17}$ It is no coincidence then that it is precisely at this point in his career that Russell dropped his former ontology of propositions as mind-independent complexes (see Russell, 1907a, 1907b), and sought instead a new theory of judgment culminating in the "multiple relations" theory of (Russell, 1910a, 1912a), included also in the introduction to PM.

Of course, dropping propositions from his metaphysics removed the motivation for trying to effect what amounts to quantification over propositional functions by quantifying over a proposition and an entity to be substituted for in it. Russell felt pulled in different directions. His solution to the paradox meant not thinking of propositional functions as independent single "things," but he needed some means for quantification over them for the purposes of his mathematical logic. In an early draft of $P M$, the tension is explicit:

A function must be an incomplete symbol. This seems to follow from the fact that $\phi !(\phi ! \hat{z})$ is nonsense. The whole difficulty lies in reconciling this with the fact that a function can be an apparent [i.e., bound] variable.

(Russell, date unknown)

The reconciliation finally came, as I shall argue in the next section, along with a new understanding of how it is that we are to understand the truth conditions of quantified statements of various orders, that is, the "hierarchy of truth and falsity" of $P M$.

16 See Linsky (2002) for a reprint of this letter, and Landini (1998); Stevens (2005) for further discussion.

17 I have developed this theme as an interpretation of Russell's general approach to paradox solving in Klement (2010). 
Russell does continue to use the word "propositions," but most of the time, he seems to mean only sentences or closed formulas, and he no longer regards them as representing extralinguistic entities, at least not on their own. Unfortunately, his usage is not quite consistent. Sometimes he calls propositions "incomplete symbols," like descriptions, or class-terms, which means they would be symbols, or parts of language. Other times, however, he calls them, "logical fictions," which would put them in the same category, not as class-terms, but as classes, that is, as what the grammar of language may mislead us into thinking of as "things," but are not really things at all. (Unfortunately, Russell himself does not always respect the distinction I am drawing here, writing, e.g., that "classes are only expressions" (Russell, 1958, p. 62) — a very misleading way of putting things.) The same sloppiness, unfortunately, infects the way he speaks in later works about "propositional functions." He sometimes describes them as expressions, parts of language (open sentences, or formulas containing variables-see Russell, 1918a, p. 133n, 1919a, p. 155ff, 1950, p. 377), but not as expressions that have meanings (even if they are meaningful). This, I take it, is what Russell means by calling them "incomplete symbols," as in the quotation above. (This does not necessarily mean that they would disappear when a contextual definition is applied; that conception of incomplete symbol applies more narrowly to descriptions and class-terms, though the latter are incomplete symbols in this broader sense as well.) Elsewhere, however, he describes them instead as "nothings," or merely apparent entities suggested to us because of our failure to understand language properly, or our mistaking an incomplete symbol for a complete one. Here are some characteristic passages:

... a propositional function in itself is nothing: it is merely a schema.

(Russell, 1918b, p. 234)

A propositional function is nothing but an expression. It does not, by itself, represent anything. (Russell, 1958, p. 53; cf., pp. 62, 92)

In the language of the second order, variables denote symbols, not what is symbolized ... . (Russell, 1940, p. 192)

We cannot afford to be similarly inconsistent. Speaking of a propositional function as an open sentence is less confusing, and I think, represents the only usage in which it makes any sense at all to say that they could be the "values" of the higher-order variables of $P M$, since on the other usage they are not, or not really, anything at all. ${ }^{18}$

\section{§5. A nominalist account.}

5.1. Soames's three worries. If the above considerations are just, then a "propositional function," for Russell, in the only sense in which he believes there is such a thing, is just an open formula. The adequacy of this understanding of propositional functions for

18 Others read Russell as having backslid to his earlier view of propositional functions as real, ambiguously-denoting denoting complexes, a view suggested by the wording at $P M$ pp. 3940. I argue against these readings in Klement (2004, p. 23ff). In fairness, it should be noted that the best contemporary realist readings of Russell's "propositional functions" are more sophisticated than those considered in earlier sections. Such readings might, for example (as in Linsky, 1999), involve treating propositional functions as constructed or derived entities rather than metaphysically basic. I leave it to those endorsing such readings to pursue the question as to whether or not this helps them escape the criticisms of the likes of Quine or Soames. 
the purposes of the no class theory has also been challenged by Soames, who succinctly summarizes these worries as follows:

For one thing, the ontology of formulas isn't innocent. Since there are infinitely many that will never be produced, they must be types-abstract sequences of existing simple expressions. And what are sequences, if not the set theoretic constructions they are standardly taken to be? On this account, the ontological "achievement" of the "no class theory" is to have eliminated classes in favor of classes. Nor would matters be helped by contending that sequences are sui generous [sic], since their formal and ontological features parallel those of classes. Then there is the logical problem. To treat predicate variables as ranging over formulas is to risk artificially limiting their range. If, as is natural, the formulas are those of a single language, then, on the standard assumption that no formula is infinitely long, the range of the variables will be restricted to a denumerable infinity-with crippling results on set theory, and the expressive power of the logic. Far from being a "technical achievement", this would be a technical slip. One could, of course, relax the usual assumptions. But then the ontology of formulas would become even more contentious, and the resulting logic more complex - with no gain in historical accuracy, since Russell didn't foresee any of this. Finally, there is the semantic problem. Arithmetical sentences aren't about language, which, on Russell's account, they would be if his predicate quantifiers ranged over formulas. For all these reasons, something else is needed as the value of a predicate variable. (Soames, 2008, p. 214)

Soames lists three problems, which we may, following him, dub the "innocence problem," the "logical problem," and the "semantic problem." I believe that once we properly understand the kind of semantics Russell intended for the higher-order "propositional function" variables and quantifiers of $P M$, we can get a sense of how he would have responded. The semantic and innocence problems simply rest on misunderstandings, and while Russell's views in $P M$ may have suffered to some extent because of the logical problem, it is wrong to say that Russell never saw it; indeed, he later made suggestions toward solving it. I conclude that, in the end, none of Soames's worries is clearly relevant to Russell's own views, at least not without significant qualification. I begin my discussion with Soames's last worry.

5.2. The semantic problem. If Russell's propositional functions are just open sentences, and they are the "values" of his higher-order variables, does his position then become one according to which mathematical statements are about language? Russell defines numbers as classes of like-membered classes. Any statement about a class is eliminated by Russell in terms of higher-order quantification. Soames seems to think that if the values of higher-order variables are open formulas then any statement involving higher-order quantification must be "about" those formulas.

This conclusion seems to me to be based on a misunderstanding concerning what sort of semantics for quantification Russell had in mind. Soames's conclusion would be justified if Russell understood higher-order quantification as objectual quantification over formulas, that is, if he would read " $\forall \phi \ldots$. as "for all open sentences ' $\ldots x \ldots$, , such-and-such is the case ...," or something along those lines. But this is the wrong reading of what Russell means by saying that the values of his higher-order variables are expressions. Instead, 
Russell means to endorse what is now called a "substitutional" account of quantification (see, e.g., Baldwin, 1979; Kripke, 1976), which means that the truth or falsity of a quantified formula depends, recursively, on the truth or falsity of those formulas obtained by replacing the variable with its possible values, where these "values" are themselves expressions, which are used, not mentioned, in the formulas so obtained. ${ }^{19}$

The substitutional account of the semantics of quantification is perhaps easiest to describe for first-order quantifiers. ${ }^{20}$ Suppose one were stating the formal semantic theory for a given object language in an appropriate metalanguage, and recursively characterizing some valuation function $v$ (used to define truth or truth in a model, etc.) A substitutional semantics might embrace such a principle as the following:

$$
\begin{aligned}
& \text { Where } w \text { is any object language variable of type } \tau \text {, and } A \text { is any } \\
& \text { formula containing } w \text { free, then } v(\ulcorner\forall w A\urcorner)=1 \text { iff, for every type- } \tau \\
& \text { constant } c \text {, it holds that } v\left(\left|\operatorname{Sub}_{c}^{w} A\right|\right)=1 \text {. }
\end{aligned}
$$

This approach characterizes the truth or falsity of a quantified statement in terms of the truth or falsity of formulas obtained from it by replacing the variable with its valid substituends. For example, " $\forall x$ ( $x$ is green)" would be assigned the value 1 (truth) just in case 1 is assigned to each of " $a$ is green", " $b$ is green", " $c$ is green", and so on for all the other individual constants in the language. Of course, for this recursion to work, it must be possible to determine the truth values of these instances independently. To adopt a substitutional interpretation of higher-order variables would in effect be to adopt such a principle with $w$ ranging over "propositional function" variables and the expressions $c$ to substitute for $w$ being open sentences of various possible complexities, depending on the type (and order) of the variable. Giving a full recursive truth definition for a language as rich as that of $P M$ is a difficult task, and outside the scope of the present paper. Suffice it to say that, for example, " $\forall F F$ ! $a$ " would be assigned 1 just in case (per impossible) every first-order sentence containing " $a$ ", for example, " $a$ is green", " $a$ is left of $b$ ", " $\forall x$ ( $a$ is left of $x \supset x$ is green)", were assigned 1 .

While Russell doesn't come close to providing a formal semantics up to contemporary standards in $P M$ (and it would be very anachronistic to expect him to have done so), the discussion of the "hierarchy" of truth and falsity in the introduction to $P M$, used to motivate the "order" or "ramified" part of type theory, suggests that Russell had something like this in mind. For example, he writes:

19 Interpretations of Russell along these lines were first suggested in such works as Grattan-Guinness (1977); Sainsbury (1979) and even hinted at in Gödel (1944), and endorsed in some form or another in Hazen (2004); Klement (2004); Landini (1998); Stevens (2005). This notion of substitution, linguistic substitution, is of a different sort than the ontological entity-for-entity sort of substitution involved in Russell's 1906 logic, though it is in some ways a natural successor of the latter given how he has now reconceived propositions.

20 There is some disagreement, even among those who attribute to Russell a substitutional semantics for higher-order variables, whether his semantics for first-order variables is also substitutional. Landini (1998, p. 277ff) suggests not, perhaps influenced by Russell's wording at Russell (1940, p. 192), quoted above. On my own view, all of Russell's quantifiers are understood substitutionally. The fact that substituends of first-order variables-logically proper namesthemselves do stand for objects, whereas the substituends of other variables do not, is, I think, enough to explain Russell's difference of attitude there. In any case, the best evidence found in $P M$ itself in favor of a substitutional reading strongly suggests a uniform treatment. This difference is not really important for the response to Soames, though if Landini were right, this illustration would be less appropriate. 
Let us call the sort of truth which is to be applicable to $\phi a$ "first truth." ... Consider now the proposition $(x)$. $\phi x$. If this has the sort of truth appropriate to it, that will mean that every value $\phi x$ has "first truth." Thus if we call the sort of truth that is appropriate to $(x) . \phi x$ "second truth", we may define " $\{(x), \phi x\}$ has second truth" as meaning "every value for $\phi \hat{x}$ has first truth", i.e. " $(x)$.( $\phi x$ has first truth)." (Whitehead $\&$ Russell, 1910, p. 42)

Given the time Russell was writing, the preinfancy of logical metatheory, we must forgive him for inappropriately using the notations and variables of the object language in places where he ought to be using the quantificational devices and notations of the metalanguage, his failure to observe the use/mention distinction carefully, and his "quantifying in" to quotation inappropriately. When interpreted charitably, I take Russell simply to be endorsing something analogous to (4) above. He goes on to describe a hierarchy of senses of truth. The details, especially the order restrictions on higher-order variables, seem motivated to ensure that the truth or falsity of any value of a propositional function could be recursively defined prior to anything using, or quantifying over, that function itself (pp. 39, 47ff), so that the truth conditions of any sentence of the language are not circular.

In short, Russell endorses a recursive theory of truth according to which the truth conditions of quantified sentences are stated in terms making reference to truth values of other sentences. This is not necessarily tantamount to endorsing a theory according to which the sentences whose truth conditions are thereby specified must be about those other sentences, or any expressions they contain. To see this, let us take disjunction as an analogy. The appropriateness of the analogy is, I think, attested by something Russell (1946) wrote much later, that sentences in which "or" or "all" (and similar logical constants) occur alike "presuppose the existence of simpler sentences in which they do not occur" (p. 154). The typical treatment of the truth conditions of a disjunctive formula within the formal semantics given for a logical language might read:

$$
\begin{aligned}
& \text { Where } A \text { and } B \text { are any formulas, } v(\ulcorner A \vee B\urcorner)=1 \text { iff either } \\
& v(A)=1 \text { or } v(B)=1 .
\end{aligned}
$$

Consider the (object-language) sentence:

$$
a \text { is green } \vee a \text { is left of } b
$$

According to (5), sentence (6) is true just in case either " $a$ is green" or " $a$ is left of $b$ " is true. The sentence I've just written is a sentence about language, and indeed, so is the more general statement (5). This is unsurprising; a formal semantic theory is of course a theory about language. None of this, however, means that (6) is about language, or about its disjuncts in particular. If its disjuncts were mentioned rather than used within it, or if, rather than using a logical connective it used a dyadic predicate, as in the rather odd (7) below, matters might be different.

$$
\text { " } a \text { is green" and " } a \text { is left of } b " \text { are disjoint. }
$$

The "iff" in (5) is simply a material biconditional. It fixes the truth conditions of disjunctions such as (6), but it does not tell us what (6) is about. Endorsing (5) is compatible with a position according to which (6) isn't about anything other than what its disjuncts are about (i.e., $a$ and $b$, their colors and positions, etc.), and that, if true, what makes it true is nothing other than what makes one or both of its disjuncts true. 
Principle (5) simply characterizes the truth conditions of a disjunction recursively in terms of the truth and falsity of certain simpler statements (its disjuncts). If I am right that Russell endorses higher-type and higher-order versions of (4), this commits him only to the view that the truth conditions of quantified formulas of a given "order" can be recursively defined in terms of the truth or falsity of either or both of formulas of lower orders whose truth conditions are independently characterizable, and, perhaps (where there are multiple successive quantifiers), also, formulas of the same order that are simpler (i.e., contain fewer quantifiers of that order). This does not commit him to the view that these quantified statements are about anything linguistic, either the other formulas in whose terms their truth can be characterized, or those open sentences whose substitution for the higher-order variables of the original yields these formulas. (And notice again, that, when substituted, these open sentences are used, not mentioned.)

It is similarly compatible with a position according to which the truth-makers (or falsitymakers, as the case might be) of such formulas are not, or need not be, linguistic in nature. Assuming, as Whitehead and Russell attempted through the definitions $* 9.01-* 9.08$ of $P M$, that quantifiers only occur at the beginning of any formula, an order $n$ closed formula with $m$ bound variables of that order will have its truth or falsity determined recursively by the truth or falsity of order $n$ formulas with at most $m-1$ bound variables of that order, and so on, until we get an order $n$ formula with only one bound variable, whose truth or falsity can be determined only in terms of the truth or falsity only of order $n-1$ formulas. Eventually, this will work its way down to the first order, and from there, down even to elementary formulas, since a first-order formula with one bound variable will have its truth or falsity determined entirely by elementary formulas. Assuming the presence (or lack thereof) of atomic facts suffices to ground the truth or falsity of such formulas, then they too suffice for the ontological grounds of quantified formulas as well. As Russell put it:

If $\phi x$ is an elementary judgment, it is true when it points to a corresponding complex [i.e., fact]. But $(x) . \phi x$ does not correspond to a single corresponding complex: the corresponding complexes are as numerous as the possible values of $x$. (Whitehead \& Russell, 1910, p. 46)

A fortiori quantified formulas are not made true by a single fact about some linguistic item, or about some nonlinguistic abstract object we might call "the function." (To be sure, a few years later, (e.g., Russell, 1918b, p. 235), Russell did introduce "general facts" and "existence facts" involved with quantification, but there is no trace of this in PM itself, and even later, it does not seem that these facts are linguistic in nature.)

Perhaps another reason to worry that a nominalistic reading of the propositional functions involved in Russell's no class theory requires thinking of statements about classes as resolving into statements about language is that the contextual definition given at $* 20.01$ makes use of the circumflex notation that Whitehead and Russell sometimes speak of as a way of speaking of "the function itself" as opposed to its values. It seems to me, however, that this can be misleading, and that we here run up against Russell's sloppiness with regard to what the function is: whether it is the expression, or the "logical fiction" that we might, in our semantic naïveté, take the expression to stand for. There are reasons however, to think that the circumflex notation-at least when it occurs in a numbered formula of $P M$ and not in informal discussion - cannot be understood as a way of mentioning or speaking about an open sentence in the object language itself. That much should be obvious from the fact that this notation is used when the circumflected variable appears in argument position 
to a function variable which is bound by a quantifier that also binds a different use of the same function variable, where there is no circumflex. Indeed, this occurs in $* 20.01$ itself:

$$
f(\hat{z} \psi z) .=:(\exists \phi): \phi ! x . \equiv_{x}, \psi x: f(\phi ! \hat{z}) \quad \text { Df. }
$$

Interpreting " $\phi ! \hat{z}$ " at the end here as a variable, which, when instantiated, would result in the name of an open sentence, rather than the use of one, is barred by the fact that we can only replace it by the use of an open sentence to make any sense of the $\phi$ occurring earlier in the definition.

How then to understand the circumflex notation? First, it is worth noting that it is actually scarcely used in $P M$, and indeed, it is questionable whether or not it is even a part of the official notation of the object language. ${ }^{21}$ In $* 20.01$, it is only necessary because the " $f$ " used in it is indefinite. It is not altogether clear how " $f$ " should be understood. The definition is applicable to any context in which an apparent class term appears, and hence, " $f$ " would seem to be utilized there like a metalinguistic schematic letter, used to represent any sentential context in which the object-language variable " $\phi$ " may appear. (Interpreting " $f$ " itself as an object-language variable is problematic, since it would then have to be restricted to a given order, and the definition is more general.) The particular instances of the schema *20.01 would in general not contain the circumflex; they would instead appear similar to the Example (1) given on page 636, where the circumflex term disappears entirely when a particular context is given. The only instances in which the circumflex would not immediately disappear when the schematic form is replaced by a particular instance occur when it appears within the argument position to a higher-type propositional function variable of the object language. To take a simple example, consider what " $\hat{x}$ is green $=\hat{x}$ is green" becomes when applying Russell's definition of identity $(* 13.01)$ :

$$
(\chi)[\chi !(\hat{x} \text { is green }) \supset \chi !(\hat{x} \text { is green })]
$$

This is not at all a statement about some entity, linguistic or otherwise, whose name is " $\hat{x}$ is green". Instead, according to the sort of semantics for quantification we have just sketched, this is a statement that will be true just in case all of the following are true:

$$
\begin{aligned}
& (x)(x \text { is green }) \supset(x)(x \text { is green }) \\
& (\exists x)(x \text { is green }) \supset(\exists x)(x \text { is green })
\end{aligned}
$$

$a$ is green $\supset a$ is green

$[(\exists x)(x$ is green $) \supset a$ is green $] \supset[(\exists x)(x$ is green $) \supset a$ is green $]$

etc.

I do not believe that any of these can be said accurately to be about the propositional function " $x$ is green" if we take the function simply to be the open sentence. To be sure, when explaining quantification informally, he sometimes paraphrases, for example, " $(\exists x)(x$ is a man)" by "the propositional function ' $x$ is a man' is sometimes true" (e.g., Russell, 1919a, p. 159) as if it mentioned the open sentence instead of using it; but I think this is loose

21 Landini (1998, chap. 10) argues that it is not, and in past works (Klement, 2003, 2004), I agreed. I now think that may have been too hasty, but it is certainly true that it is used only in certain very peculiar circumstances, and is not, like the lambda abstracts of Church's lambda calculus, something pervading the system, so that concretion and expansion rules would be necessary, etc. Russell's notation does not have something like " $((x), \hat{\phi} x) F \hat{z}$ " but just " $(x) . F x$ ", and is rather more like Frege's in that regard. I explore these issues in much greater detail in Klement (forthcoming). 
talk phrased for the benefit of an audience that, in general, would have had almost no familiarity with modern quantificational logic. Russell's point is simply that the existential statement is true just in case the function is sometimes satisfied, that is, has true instances. Again, to take the analogy with disjunction, (6) is true just in case (7) is true, but that does not mean that (6) says something about its disjuncts, the way that (7) does. Indeed, Russell (1919a) explicitly says that we "more correctly" speak of "functions of functions" than "statements about functions" (p. 186). Similar considerations apply to all contexts in which the circumflex notation is used in $P M$, and hence, that such notation does not, even on the nominalist view sketched here, commit Russell to the view that an analyzed statement about a class turns out to be a statement about language.

I believe the above considerations suffice to show that Soames's "semantic problem" is not a problem at all for Russell. Yes, arithmetical statements turn out, on analysis, to be statements in which higher-order quantifiers are used, and the "values" of these variables, insofar as they have them, are open formulas. But again, they are "values" only in the substitutional, not the objectual, sense. The quantified statements are not about these formulas, and hence, Russell is not committed to the view that mathematical statements (or statements about classes generally) are about language.

5.3. The innocence problem. I believe the considerations just given in reaction to the semantic problem show that Russell is not really giving us, as Soames seems to think, a reduction of classes to language. Russell is not replacing an ontology of classes with an ontology of formulas. Hence, one might argue that Russell's no class theory is not really committed to any particular view about the ontology of formulas or the nature of language generally. Nevertheless, perhaps something remains of Soames's complaint that the "ontology of formulas is not innocent," even once this misleading impression is removed. Russell's no class theory is only plausibly a success given the kind of semantic theory he gives for his language. It is not customary even now to demand that someone giving a formal semantics for a language provide a theory about the metaphysical nature or ontological reality of the various expressions of the object language, and it is perhaps unfair to expect Russell to have done so. Nevertheless, if it were simply impossible to account for the reality or ontological status of linguistic formulas in a way that didn't presuppose ontologically real or ineliminable classes or something similar, as Soames seems to imply, there would still be an objection to Russell's theory. (Of course, the same would be true if there were anything it were impossible to account for without ontologically real or ineliminable classes.)

However, I do not think this is the case. Of course, in interpreting Russell as holding a nominalism about propositional functions, I am not attributing to him a nominalism about simple universals, that is, the constituents of atomic facts, which Russell clearly takes realistically. ${ }^{22}$ Russell says very little about the nature of linguistic expressions during this period, but in later works he seems to think of words (or at least word types, rather than word tokens, which are involved here) as universals:

The word 'dog' is a universal, just as $d o g$ is a universal. We say, loosely, that we can utter the same word 'dog' on two occasions, but in fact we

22 See, for example, Russell (1911b, 1912a). Indeed, prior to Wittgenstein's influence, Russell still held that simple universals could occur in the logical subject position of atomic propositions (Russell, 1911a, pp. 94-95), which of course shows he didn't equate them with propositional functions of any type. See also Notes 3 and 10. 
utter two examples of the same species, just as when we see two dogs we see two examples of the same species. (Russell, 1940, p. 22; cf., 1946, pp. 157-58)

Now, it is probably not a complete response to suggest that Russell can identify each formula of his language with a distinct universal, deny that universals are classes, and leave it at that. Something like this might be true for individual words (although even that is doubtful), but formulas, importantly, are sequences of parts, having a structure, as Soames stresses. It is again, not altogether clear, however, that this structure has to be thought of set-theoretically; we may be dealing with a more fundamental kind of structure. While Russell no longer believes in structured objective propositions, he does believe in facts, and sometimes describes "word propositions" as themselves facts, sharing a common structure with the facts to which they point (Russell, 1919b, p. 309, 1921, p. 276, Whitehead \& Russell, 1925, app. C)—a view perhaps influenced by the "picture theory" of Wittgenstein's Tractatus. Still, one might worry that this applies more to the tokens, rather than the types, of the formulas. As Soames stresses, there must be some types of which there are no tokens.

Is there anything standing in the way of Russell understanding the structure, or sequential nature, of formulas, by treating them precisely as he treats mathematical sequences or ordered classes, the expressions for which are eliminated by his contextual definitions? That is, is there anything in the way of Russell regarding any claim made "about" a formula as a claim "about" a sequence understood class-theoretically, with these classes understood as eliminable rather than fundamental? Russell himself, later on, sometimes even in the same works in which he calls words "universals," also calls them "classes" (Russell, 1940, p. 22, 1946, p. 157, and cf., 1919b, p. 290). Indeed, at times he explicitly identifies sentences, propositions, and sometimes even words with series of types of sounds or written marks, or classes thereof (Russell, 1921, pp. 189, 241; Whitehead \& Russell, 1910, app. C). He seems to be thinking of them class-theoretically, ${ }^{23}$ but still in an eliminable sense. In 1923, he even wrote, "A word is a class of series, and both classes and series are logical fictions" (Russell, 1923, p. 152n).

Is the adoption of such a view circular or viciously regressive for Russell? I fail to see how. It is tantamount to the claim that the name for a formula (closed or open) - that is, a name used to mention rather than use a formula-ought to be regarded as an incomplete symbol ostensibly about a "class" or "relation-in-extension," to be eliminated contextually in terms of propositional function variables. There would also have to be a propositional function defining the membership of the class or relation-in-extension which the formula "is." When the statement about the formula is analyzed, this propositional function would be used, not mentioned. The analysands, therefore, while using a distinct propositional function, would not be about that other function, and the truth or falsity of the analyzed claim would not involve this other propositional function as an "object." This view does give rise to a kind of infinite regress, since if we did want to form a proposition about this new propositional function - the one used when we analyze a claim in which the original is mentioned - we would have to invoke (i.e., use, not mention) a third propositional function defining the class-theoretic whatnot we are thinking of the second function as. (And we'd have to invoke a fourth one to capture truths about this third one, and so on.) However,

23 Strictly speaking, Russell would regard a series as a relation-in-extension, not a class, but since his contextual definitions of the two are so similar, the difference is not important for the present discussion. 
it does not seem to me that there is anything vicious about this regress. Perhaps it would be vicious if the metaphysical grounds of the truth or falsity of those formulas in which a given propositional function is used depended on truths about that propositional function. However, as I have already argued, this is not the case.

To be clear, I do not think Russell's no class theory alone forces him to the position that when we analyze claims about formulas, we must think of them as classes or set theoretic "objects." My thesis is the modest one that even if this were how formulas should or must be understood, it would not point to a fatal flaw within Russell's method of eliminating classes. I shall also mention in passing that Russell's theory of types places grammatical restrictions on what contexts certain propositional functions can be used within. It does not tell us what logical type the expressions to be used when we mention propositional functions must have. There is nothing so far as I can see preventing Russell from holding that these expressions all occupy the same type. If this is right, then Russell's type theory completely escapes another common concern: that it cannot be stated without violating its own strictures. The claim that a given function has a certain type is a claim in which that function is mentioned, not used; therefore it can be perfectly meaningful to say of two functions of different types that they are of different types, and so on; indeed, Whitehead \& Russell (1910, p. 48) tell us as much. ${ }^{24}$

5.4. The logical problem. What Soames calls "the logical problem," is, I think, the greatest cause for concern for Russell's no class theory. Indeed, I think Russell's views at the time of the 1910 first edition of $P M$, taken together, are susceptible to a version of the problem. However, I shall argue, contrary to Soames's claim that "Russell didn't foresee any of this," that Russell did not remain completely unaware of this and related difficulties in subsequent years. Instead, I shall point to various ways in which his views moved in the direction of a position that might provide an adequate response to the logical problem. Even on a substitutional interpretation of what it means for open sentences to be "values" of the variables, where higher order quantifiers do not simply mean something such as "for all open formulas of the type ...," it is still true that if there were only denumerably many open formulas of a given type, the truth or falsity of quantified statements formed with variables for that type would depend recursively on only denumerably many sentences. This is a problem if such quantified statements are to be used to proxy quantification over a greater than denumerably infinite number of classes. As Soames (2008) notes in footnote (p. 214n), ranging over nondenumerably infinite collections (e.g., all subclasses of the natural numbers) is essential to the "expressive distinctness" of higher-order logic (the categoricity of second-order arithmetic, etc.) Russell, of course, in 1910, wasn't aware of the metatheoretic differences between first- and higher-order logic, so this could not have been his motive for using a higher-order system. Yet, he clearly did accept that the number of subclasses of a denumerable type should be nondenumerable (e.g., Russell, 1919a, p. 86).

Soames's claim that there can only be denumerably many formulas of a given language is a commonly accepted one. He points to "the standard assumption that no formula is infinitely long." Actually, however, to obtain the conclusion that there are at most denumerably many formulas, one needs, in addition to Soames's assumption, an additional one:

24 Rather frustratingly, Soames (2003, p. 154) accuses Russell's theory of types of being a theory that cannot be stated without violating its own strictures. Soames's complaint is a straw man, however, since it only applies to Soames's (knowingly!) oversimplified version of Russell's theory in which classes are treated as entities. 
that the language in question has no more than denumerably many primitive symbols. Unfortunately, as of 1910, Russell seems to have accepted both assumptions, since, in discussing definitions, he claimed that "the total number of possible definitions is $\aleph_{0}$ " $(P M$, p. 61), and his rationale for this seems to have been that this is all that is possible using a finite number of words arranged into formulas of finite length. This does indeed pose a problem for his views of the time, since he then accepted that there are more than $\aleph_{0}$ members of some types of classes, but on the no class theory, there cannot be classes which are not defined by a propositional function. ${ }^{25}$

As his views developed, and Russell came more and more to think in terms of a logically ideal language (peaking, perhaps, in the late 1910s and early 1920s), he developed attitudes at odds not only with the assumption Soames explicitly made concerning no formula being infinitely long, but also the one Soames assumes without comment. Perhaps Soames didn't think this additional assumption worth mentioning, since it is nearly always taken for granted that a language must only have finitely many primitive symbols. The meanings of primitive symbols must be learned individually, and so languages with more than finitely many primitive symbols would be unlearnable (and a fortiori those with more than denumerably many). However, the argument really only shows that such a language would not be learnable in its entirety. Russell explicitly claimed that one does not have to understand the full vocabulary of a language in order to comprehend its logical principles and conduct mathematical proofs in it. For example, in 1919, he writes:

[In t]he language of mathematical logic, if it were perfected... [w]e should not need to know any words, because they would only be needed for giving values to the variables, which is the business of the applied mathematician, not of the pure mathematician or logician. It is one of the marks of a proposition of logic that, given a suitable language, such a proposition can be asserted in such a language by a person who knows the syntax without knowing a single word of the vocabulary. (Russell, 1919a, pp. 200-201)

The passage is interesting in multiple ways. Russell suggests that nonlogical vocabulary is needed "to give values to variables," even the variables used in mathematics, but that a working mathematician need not understand that vocabulary. In another work of the period, he suggests that even a logically perfect language would be one in which much of the vocabulary would be private to individuals (Russell, 1918b, p. 198). His reason for this is that, according to his theory of propositional understanding, we only understand a simple symbol if we are directly acquainted with what it means. As we are all acquainted with different particulars (sense data), typically our shared vocabulary would include only expressions for universals/relations and logical constants. Russell rejects the supposition that a language must be fully learnable by any one individual. (And indeed, with regard to actual languages, it is doubtful whether anyone ever has learned a language in its entirety, even where it is theoretically possible.)

25 Even here, though, there are questions that can be raised. The quotation about the number of possible definitions occurs within the set up of his discussion of the König-Dixon paradox. In the solution, he seems to think that the number of names and definitions at certain levels of a hierarchy of languages is always limited, but that there is no limit to what is nameable or definable in toto (p. 64). Moreover, in the discussion of Richard's paradox which immediately follows, he is more cautious, claiming only that at most $\aleph_{0}$ decimals can be defined "by means of a finite number of words" (p. 61), leaving the door open to definitions that use more than a finite number of words. 
Russell's "logically perfect language" would have as many simple symbols as there are simple things:

In a logically perfect language, there will be one word and no more for every simple object, and everything that is not simple will be expressed by a combination of words, or a combination derived, of course, from the words for the simple things that enter in, one word for each simple component ... . The language which is set forth in Principia Mathematica is intended to be a language of that sort. It is a language which has only syntax and no vocabulary whatsoever. ... It aims at being the sort of language that, if you add a vocabulary, would be a logically perfect language. (Russell, 1918b, p. 198)

Elsewhere he claims that "a complete symbolic language," would have "a definition for everything definable, and an undefined symbol for everything indefinable," going on to argue that even his theory of descriptions does not allow "a perfect language to dispense with names for all particulars" (Russell, 1919a, pp. 182-83). How many simple symbols there would be in his language then, depends on how many simple individuals there are. And while Russell is notoriously uncertain about whether or not there are infinitely many individuals, despite the potentially harmful consequences there might be to his treatment of mathematics if there are not, ${ }^{26}$ his position is compatible with there being even nondenumerably many simple things, and if there are, then he would hold that there would have to be nondenumerably many names in his language as well, and in that case, there would also be nondenumerably many formulas as well.

As strange as the idea of a potential language with infinitely many simple symbols seems to us, the notion did not seem strange to a well-known student of Russell, who once wrote:

What the axiom of infinity is intended to say would express itself in language through the existence of infinitely many names with different meanings. (Wittgenstein, 1961, §5.535)

And recall furthermore that for Wittgenstein, a "name cannot be dissected any further by means of a definition: it is a primitive sign" (\$3.261).

Moreover, there is evidence that Russell did not always fully accept the other assumption - the one explicitly mentioned by Soames - that a formula must be finitely long. Russell's treatment only accommodates those classes definable as the extension of a (predicative) propositional function. This would seem to rule out defining a class by enumeration of its members. However, this is not always so, since the class whose members are $a, b$, and $c$ can be defined in terms of the propositional function " $x=a \vee x=$ $b \vee x=c "$, or something along those lines. The difficulty of course is that if there are infinitely many such members, this strategy seems inapplicable. In a review of Ramsey's Foundations of Mathematics, Russell (1931) admits that it's a mistake to think that "all classes and relations in extension are definable by finite propositional functions" (p. 108), and accepts it as a defect of $P M$ that it suggests otherwise. Yet, Russell seems sympathetic

26 See Russell (1919a, chap. 13). In $P M$ itself, rather than assuming an "axiom" of infinity, a principle asserting an infinity of individuals is used as an undischarged antecedent on various results that require such an assumption, including the fourth Peano postulate to the effect that no natural number is identical with its successor, and all mathematical results that depend on this principle. If this antecedent were untrue, of course, it arguably would trivialize many aspects of the "reduction" of mathematics to logic. 
with the suggestion that "there is no logical objection to the definition of an infinite class by enumeration," claiming only that "We cannot define an infinite class in this way because we are mortal, but our mortality is an empirical fact which logicians should ignore" (Russell, 1958, p. 91; cf., 1932). This seems to suggest an openness to the possibility of infinitely long propositional functions, even if they cannot actually be produced. Since Russell does not identify expressions with tokens of them, infinitely long ones are not obviously impossible, though Russell perhaps owes us a fuller account of them.

This also relates to what Russell says about the Axiom of Reducibility, which holds that every nonpredicative propositional function is equivalent (coextensional) with a predicative one. In Introduction to Mathematical Philosophy, Russell (1919a) describes the principle as a "generalised form of Leibniz's identity of indiscernibles" (p. 192). What he has in mind is roughly this: assume that the conjunction of all predicative propositional functions satisfied by a given individual could not be satisfied by any other individual (which is one way of interpreting Leibniz's principle). In that case, if one takes the disjunction of all such conjunctions for the individuals satisfying a given nonpredicative propositional function, the result will be a complex coextensive predicative propositional function, and hence that the axiom will be true in that instance. Russell even suggests that the axiom will not be necessary if the number of objects satisfying the nonpredicative function is finite, since the coextensive predicative function might actually be produced (Whitehead \& Russell, 1910, p. 56). But clearly, Russell's suggestion that the axiom is itself to be regarded as a generalized form of Leibniz's principle suggests that he would think, even if it couldn't be humanly produced, that the associated coextensional predicative function exists even for those satisfied by infinitely many things. To be sure, Russell (1919a) does not himself seem fully convinced of this as a defense of the Axiom of Reducibility, but his doubts seem to stem entirely from skepticism about the identity of indiscernibles, so interpreted (p. 192). ${ }^{27}$ He does not seem concerned that the predicative function so generated might need to be infinitely complex. Indeed, not only does the Axiom of Reducibility seem more plausible if infinite formulas are allowed, but so does what Russell calls "the multiplicative axiom," which is much like the axiom of choice, except that, when fully analyzed à la Russell, it postulates certain propositional functions rather than "choice sets."

A few years later, in the second edition of $P M$, Russell also considers a possible way of getting around the need for such an axiom that makes use of "infinite conjunctions and disjunctions" to do the work of nonpredicatively quantified formulas, but complains that "in practice, an infinite conjunction or disjunction ... cannot be manipulated without assumptions $a d$ hoc" (p. xxxii). The suggestion seems to be that while infinite disjunctions and conjunctions are not themselves impossible (and hence might make up values of variables, substitutionally considered), it would not be possible to set up inference rules for using them "in practice," and hence, that they may not obviate the need for assuming Reducibility as an axiom.

I think it can be concluded from the above that Soames's "logical problem" might, in the end, not be such a problem for Russell after all. In this case, however, I am less confident that the response I have offered for Russell is fully adequate, especially in that it raises other problems for which Russell might have no easy answer. As we have seen, it seems to leave Russell postulating the existence of a "logically perfect language," which seems more of an

27 One must use a disjunction of conjunctions of predicative functions rather than a disjunction of identities such as " $x=a \vee x=b \vee x=c \ldots$ ", because identity is defined in $P M$ using a higher-order quantifier and thus would create an nonpredicative function here. 
abstract possibility than anything that even in principle could be created. Even if we accept that no one individual would need to understand the entirety of the language, Russell's proposal still faces the difficulty that the language couldn't be understood (or created) by even a finite number of individuals assuming it really were to have nondenumerably infinitely many primitive symbols. Especially given Russell's "robust sense of reality", that is, his skepticism about unreal or merely potential entities, it is unclear to what extent Russell is warranted in claiming that we can "assume that we have constructed a logically perfect language, and that we are going on State occasions to use it" (Russell, 1918b, p. 198). If such a language isn't now, or I daresay ever, in use, in what sense is it there, to "give values to the variables" used in mathematics? ${ }^{28}$ Similarly, if Russell were to accept infinitely complex formulas, the recursive truth conditions for those formulas would have to be more complicated than even what I briefly sketched in Section 5.2, involving transfinite recursion of some sort, and nothing he has written indicates how this might be done. Perhaps these worries could be regarded as highly qualified or more specific versions of Soames's original worries, but it also seems to me that Russell is in a far better position than the impression one would get from reading Soames. Indeed, Russell's position is far from hopeless. Perhaps these worries could be overcome by a clever sympathizer with Russell's approach.

§6. Conclusion. My own aim, however, has not been to endorse Russell's position, but simply to try to clarify what it is, and demonstrate that it is far more sophisticated than it is often taken to be. As we have seen, Russell was driven to reject both classes and extralinguistic correlates of open sentences as parts of his philosophical solutions to (various versions of) Russell's paradox. In fact, I think one cannot really understand what Russell's proposed solution to the logical paradoxes was without understanding how it is that these paradoxes changed his overall orientation on ontology. ${ }^{29}$ Whereas Russell began with a robust ontology of abstracta, he realized that this tendency to reify left him without a way of addressing the paradoxes. In 1910, he wrote:

I have ... discovered that it is possible to give an interpretation to all propositions which verbally employ classes, without assuming that there really are such things as classes at all... That it is meaningless ... to regard a class as being or not being a member of itself, must be assumed for the avoidance of a more mathematical contradiction; but I cannot see that this could be meaningless if there were such things as classes. (Russell, 1910b, p. 376)

The same consideration applies to propositional functions treated as extralinguistic "things": if they were such, there would be no escaping the question as to whether or not they satisfy themselves. Instead, to speak of a "propositional function" is a way of speaking of those formulas that can be obtained from one another by the right kinds of substitution,

28 In discussing related issues for Russell, Bostock (2008, p. 135) hints at an interpretation of variables whereby they can be seen as "taking the place" of names or open sentences, but not necessarily only those we happen to have expressions for. Unfortunately, he leaves this suggestion undeveloped, but at first blush, it is unclear precisely what it would mean to have interpretations of variables that are place-holders for open sentences which are not themselves open sentences "we have expressions for."

29 I discuss this at greater length in Klement (2010). 
and they must be divided into types simply because the expressions to be substituted can be of different sorts of syntactic complexity, and those of the wrong sort quite simply don't fit in the spots into which they would be substituted.

In the end, Russell was left without any ontology at all of abstract mathematical or logical objects like classes or functions. When properly analyzed, any mathematical statement turns out to be a complicated statement involving higher-order quantification, and no independently referential parts (cf., Russell, 1919a, chap. 18). These higher-order formulas have their truth or falsity determined recursively by the lower-order formulas obtained by substituting for the bound variables, and hence, ultimately, on elementary propositions. Here, I think, we have insight into what Russell meant by claiming that his "logical atomism" is a view that "forced itself" upon him "in the course of thinking about the philosophy of mathematics" (Russell, 1918b, p. 178). The intended semantics for Russell's ideal language is one in which all truths are ultimately grounded in those of the simplest sort. ${ }^{30}$ His proposed language is one in which, in Russell's words, only the "ultimate furniture" (Russell, 1919a, p. 182) of the world is represented by simple symbols, and in which complex expressions, although perhaps meaningful, although they may appear to mean "complex things," in fact have a different function altogether than to refer to things. Indeed, the atomist Russell did not believe in "complex things" (apart from facts) at all (Russell, 1918b, p. 190).

This reading also, I think, sheds light on what Russell took to be the outstanding questions in his philosophy of logic after the publication of (the first edition of) PM. During the period in which Russell was a realist about propositions, variables, and propositional functions, he held that one could regard the form of a proposition-what he then called a "mode of combination"- - as being a propositional function taken as a unity much like the proposition but with variables in place of all the definite entities in the proposition; thus the "form" of a proposition involving a binary relation between two individuals would be $\hat{x} \hat{R} \hat{y}$ (see, e.g., Russell, 1904c). When Russell gave up thinking of either propositions or propositional functions as "real," he still believed that facts had forms, but admitted to having trouble understanding what sort of thing a form could be (see, e.g., Russell, 1912b). This is a problem he discussed with Wittgenstein in 1912, and hoped Wittgenstein might be able to solve.

Russell's "no class" theory of classes, and the understanding of higher-order quantification that underlies it, are certainly not without unresolved philosophical questions and issues that perhaps need further scrutiny. (Substitutional quantification itself has its detractors, although I think we have already considered some of the more common objections.) Nevertheless, I hope to have made it fully clear that Russell was himself aware that simply offering a contextual definition of classes in terms of quantification using propositional function variables was not in itself a philosophical achievement or ontological elimination. Without a supporting theory of the nature of "propositional functions," or, failing that, an account of higher-order quantification, that was free of commitment to equally dubious entities, the no class theory would have been just as unacceptable to Russell as it seems to be to Quine and Soames. Russell spent years of his life struggling with these issues. While even at the time Russell admitted that the official view of $P M$ may not be the final solution, and that modified versions might still be worth exploring (Whitehead \& Russell,

30 I take this to be true even when, later, Russell introduced general and existence facts, since these seem to be something like "metafacts", grounded in precisely what elementary or atomic facts there are or aren't. 
1910, p. vii), I think it cannot be denied that it is a fascinating and forceful proposal, still worth taking seriously by contemporary philosophers.

Soames $(2006$, pp. 655,661$)$ accuses some scholars with an "antiquarian" fascination with minor details of history, as opposed to truly important insights that continue to demand the attention of philosophical practitioners. However, many of the problems that drove Russell to develop the precise views he did, according to which not only classes, but propositions, propositional functions, etc., are rejected as extralinguistic "complex entities," are relevant to contemporary projects, in ways that current practitioners don't seem to fully realize. Indeed, the kinds of Cantorian paradoxes that led Russell to abandon not only classes as entities, but structured propositions, and structured objective "propositional functions" along with them, have no commonly accepted solution, despite widespread belief in such things or things relevantly similar (cf., Deutsch, 2008; Klement, 2010). Where better to start looking for a solution to these problems than with their discoverer?

\$7. Acknowledgments. For helpful comments on previous drafts, thanks to Ian Proops, Chris Pincock, Ray Perkins, and the audience of the Bertrand Russell Society Annual Meeting at Central Connecticut State University in June 2009.

\section{BIBLIOGRAPHY}

Baldwin, T. (1979). Interpretations of quantifiers. Mind, 88, 215-240.

Bostock, D. (2008). Russell on 'the' in the plural. In Griffin, N. and Jacquette, D., editors. Russell vs. Meinong: The Legacy of “On Denoting”. New York: Routledge, pp. 113-143. Cartwright, R. (2005). Remarks on propositional functions. Mind, 114, 915-927.

Church, A. (1976). Comparison of Russell's resolution of the semantical antinomies with that of Tarski. Journal of Symbolic Logic, 41, 747-760.

Deutsch, H. (2008). Review of J. C. King, The Nature and Structure of Content. Notre Dame Philosophical Reviews. Available from: http://ndpr.nd.edu/review.cfm?id=13165.

Frege, G. (1980). Philosophical and Mathematical Correspondence (B. McGuinness, translator; Hans Kaal, editor). Chicago: University of Chicago Press.

Frege, G. (1984). On concept and object. In McGuinness, B., editor. Collected Papers on Mathematics, Logic and Philosophy. New York: Basil Blackwell, pp. 182-194. (First published 1892).

Geach, P. (1972). Logic Matters. Oxford: Blackwell.

Gödel, K. (1944). Russell's mathematical logic. In Schilpp, P., editor. The Philosophy of Bertrand Russell, Vol. I. New York: Harper \& Row, pp. 123-153.

Grattan-Guinness, I., editor. (1977). Dear Russell-Dear Jourdain. New York: Columbia University Press.

Hazen, A. P. (2004). A "constructive" proper extension of ramified type theory. In Link, G., editor. One Hundred Years of Russell's Paradox. Berlin: Walter de Gruyter, pp. 449-480.

Klement, K. C. (2002). Frege and the Logic of Sense and Reference. New York: Routledge.

Klement, K. C. (2003). Russell's 1903-05 anticipation of the lambda calculus. History and Philosophy of Logic, 24, 15-37.

Klement, K. C. (2004). Putting form before function: Logical grammar in Frege, Russell and Wittgenstein. Philosopher's Imprint, 4, 1-47.

Klement, K. C. (2005). The origins of the propositional functions version of Russell's paradox. Russell, 24, 101-32.

Klement, K. C. (2010). Russell, his paradoxes, and Cantor's theorem: Part 2. Philosophy Compass, 5, 29-41. 
Klement, K. C. (forthcoming). PM's circumflex, syntax and philosophy of types. In Linsky, B., and Griffin, N., editors. Principia Mathematica at 100.

Kremer, M. (2006). Review of Scott Soames, Philosophical Analysis in the Twentieth Century. Notre Dame Philosophical Reviews. Available at: http://ndpr.nd.edu/review. cfm?id=4061.

Kremer, M. (2008). Soames on Russell's logic: A reply. Philosophical Studies, 139, 209_ 212.

Kripke, S. (1976). Is there a problem about substitutional quantification? In Evans, G., and McDowell, J., editors. Truth and Meaning. Oxford: Clarendon Press, pp. 325-419.

Landini, G. (1998). Russell's Hidden Substitutional Theory. Oxford: Oxford University Press.

Linsky, B. (1988). Propositional functions and universals in Principia Mathematica. Australasian Journal of Philosophy, 66, 447-460.

Linsky, B. (1999). Russell's Metaphysical Logic. Stanford, CA: CSLI Publications.

Linsky, B. (2002). The substitutional paradox in Russell's 1907 letter to Hawtrey [corrected reprint]. Russell, 22, 151-160.

Linsky, B. (2004). Russell's marginalia in his copies of Frege's works. Russell, 24, 5-36.

Pincock, C. (2005-2006). Review of Scott Soames, Philosophical Analysis in the Twentieth Century. Russell n.s. 25, 167-172.

Proops, I. (2006). Soames on the metaphysics and epistemology of Moore and Russell. Philosophical Studies, 129, 627-35.

Quine, W. V. (1980). Logic and the reification of universals. In From a Logical Point of View (second edition). Cambridge, MA: Harvard University Press, pp. 102-129. (First edition 1953).

Quine, W. V. (1981). Russell's ontological development. In Theories and Things. Cambridge, MA: Harvard University Press, pp. 73-85. (First published 1966).

Quine, W. V. (1995). Whitehead and the rise of modern logic. In Selected Logic Papers. Cambridge, MA: Harvard University Press, pp. 3-36. (First published 1941).

Russell, B. (1903a). Dependent variables and denotation. In Urquhart, A., editor. The Collected Papers of Bertrand Russell, Vol. 4. London: Routledge, pp. 297-304.

Russell, B. (1903b). Functions. In Urquhart, A., editor. The Collected Papers of Bertrand Russell, Vol. 4. London: Routledge, pp. 49-74.

Russell, B. (1903c). On meaning and denotation. In Urquhart, A., editor. The Collected Papers of Bertrand Russell, Vol. 4. London: Routledge, pp. 314-358.

Russell, B. (1903d). On the meaning and denotation of phrases. In Urquhart, A., editor. The Collected Papers of Bertrand Russell, Vol. 4. London: Routledge, pp. 283-296.

Russell, B. (1903e). Points about denoting. In Urquhart, A., editor. The Collected Papers of Bertrand Russell, Vol. 4. London: Routledge, pp. 305-313.

Russell, B. (1903f). The Principles of Mathematics. Cambridge, UK: Cambridge University Press. (Second edition 1931).

Russell, B. (1904a). Fundamental notions. In Urquhart, A., editor. The Collected Papers of Bertrand Russell, Vol. 4. London: Routledge, pp. 111-263.

Russell, B. (1904b). Meinong's theory of complexes and assumptions. In Urquhart, A., editor. The Collected Papers of Bertrand Russell, Vol. 4. London: Routledge, pp. 431474.

Russell, B. (1904c). On functions. In Urquhart, A., editor. The Collected Papers of Bertrand Russell, Vol. 4. London: Routledge, pp. 96-110.

Russell, B. (1904d). On functions, classes and relations. In Urquhart, A., editor. The Collected Papers of Bertrand Russell, Vol. 4. London: Routledge, pp. 85-95. 
Russell, B. (1904e). On the nature of functions. In Urquhart, A., editor. The Collected Papers of Bertrand Russell, Vol. 4. London: Routledge, pp. 265-272.

Russell, B. (1905a). The nature of truth. In Urquhart, A., editor. The Collected Papers of Bertrand Russell, Vol. 4. London: Routledge, pp. 492-493.

Russell, B. (1905b). On classes and relations. In Urquhart, A., editor. The Collected Papers of Bertrand Russell, Vol. 4. London: Routledge, pp. 273-279.

Russell, B. (1905c). On denoting. In Urquhart, A., editor. The Collected Papers of Bertrand Russell, Vol. 4. London: Routledge, pp. 414-427.

Russell, B. (1905d). On fundamentals. In Urquhart, A., editor. The Collected Papers of Bertrand Russell, Vol. 4. London: Routledge, pp. 359-413.

Russell, B. (1906a). On 'insolubilia' and their solution by symbolic logic. In Lackey, D., editor. Essays in Analysis. New York: George Braziller, pp. 190-214.

Russell, B. (1906b). The substitutional theory of classes and relations. In Lackey, D., editor. Essays in Analysis. New York: George Braziller, pp. 165-189.

Russell, B. (1907a). Logic in Which Propositions Are Not Entities. Unpublished manuscript, Bertrand Russell Archives, McMaster University.

Russell, B. (1907b). On the nature of truth. Proceedings of the Aristotelian Society, 7, $28-49$.

Russell, B. (1907c). The Paradox of the Liar. Unpublished manuscript, Bertrand Russell Archives, McMaster University.

Russell, B. (1908). Mathematical logic as based on the theory of types. American Journal of Mathematics, 30, 222-262.

Russell, B. (1910a). On the nature of truth and falsehood. In Philosophical Essays. New York: Longmans \& Green, pp. 140-151.

Russell, B. (1910b). Some explanations in reply to Mr. Bradley. Mind, 19, 373-378.

Russell, B. (1911a). Analytic realism. In Mumford, S., editor. Russell on Metaphysics. London: Routledge, pp. 91-96.

Russell, B. (1911b). On the relations of universals and particulars. In Marsh, R. C., editor. Logic \& Knowledge. London: George Allen \& Unwin, pp. 105-124.

Russell, B. (1912a). The Problems of Philosophy. London: Home University Library.

Russell, B. (1912b). What is logic? In Slater, J. G., editor. The Collected Papers of Bertrand Russell, Vol. 6. London: Routledge, pp. 54-56.

Russell, B. (1914). Our Knowledge of the External World. Chicago: Open Court.

Russell, B. (1918a). On the notion of cause. In Mysticism and Logic. London: George Allen \& Unwin, pp. 132-151. (First published 1912).

Russell, B. (1918b). The philosophy of logical atomism. In Marsh, R. C., editor. Logic \& Knowledge. London: George Allen \& Unwin, pp. 175-281.

Russell, B. (1919a). Introduction to Mathematical Philosophy. London: George Allen \& Unwin.

Russell, B. (1919b). On propositions: what they are and how they mean. In Marsh, R. C., editor. Logic \& Knowledge. London: George Allen \& Unwin, pp. 283-320.

Russell, B. (1921). The Analysis of Mind. London: Allen \& Unwin.

Russell, B. (1923). Vagueness. In Slater, J. G., editor. The Collected Papers of Bertrand Russell, Vol. 9. London: Unwin Hyman, pp. 147-154.

Russell, B. (1924). Logical atomism. In Marsh, R. C., editor. Logic \& Knowledge. London: George Allen \& Unwin, pp. 323-343.

Russell, B. (1931). Review of Ramsey, The Foundations of Mathematics. In Slater, J. G., editor. The Collected Papers of Bertrand Russell, Vol. 10. London: Routledge, pp. 107114. 
Russell, B. (1932). [Another] Review of Ramsey, The Foundations of Mathematics. In Slater, J. G., editor. The Collected Papers of Bertrand Russell, Vol. 10. London: Routledge, pp. 114-117.

Russell, B. (1940). Inquiry into Meaning and Truth. London: George Allen \& Unwin.

Russell, B. (1946). The problem of universals. In Mumford, S., editor. Russell on Metaphysics. London: Routledge, pp. 143-159.

Russell, B. (1950). Logical positivism. In Marsh, R. C., editor. Logic \& Knowledge. London: George Allen \& Unwin, pp. 365-382.

Russell, B. (1958). My Philosophical Development. London: George Allen \& Unwin.

Russell, B. (date unknown). Types (draft). Unpublished manuscript, Bertrand Russell Archives, McMaster University.

Sainsbury, R. M. (1979). Russell. London: Routledge and Kegan Paul.

Sainsbury, R. M. (2006). Review of Scott Soames, Philosophical Analysis in the Twentieth Century. Philosophical Studies, 129, 637-43.

Soames, S. (2003). Philosophical Analysis in the Twentieth Century: Volume 1: The Dawn of Analysis. Princeton, NJ: Princeton University Press.

Soames, S. (2006). What is history for? Reply to critics of The Dawn of Analysis. Philosophical Studies, 129, 645-665.

Soames, S. (2008). No class: Russell on contextual definition and the elimination of sets. Philosophical Studies, 139, 213-218.

Soames, S. (forthcoming). Propositions. In Graff Fara, D., and Russell, G., editors. The Routledge Companion to the Philosophy of Language. Abingdon: Routledge.

Stevens, G. (2005). The Russellian Origins of Analytical Philosophy. London: Routledge.

Whitehead, A. N. (1898). A Treatise on Universal Algebra. Cambridge, UK: Cambridge University Press.

Whitehead, A. N., \& Russell, B. (1910). Principia Mathematica (3 Volumes, first edition). Cambridge: Cambridge University Press.

Whitehead, A. N., \& Russell, B. (1925). Principia Mathematica (3 Volumes, second edition). Cambridge: Cambridge University Press.

Wittgenstein, L. (1961). Tractatus Logico-Philosophicus. London: Routledge. Translator D. Pears and B. McGuinness. (First published 1921).

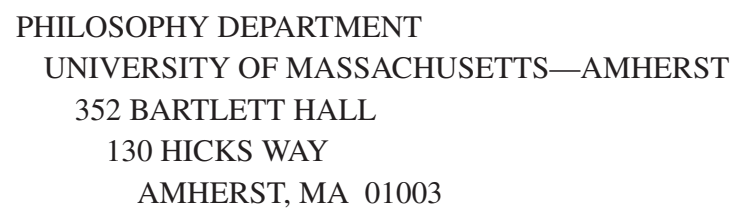

PHILOSOPHY DEPARTMENT

UNIVERSITY OF MASSACHUSETTS-AMHERST

352 BARTLETT HALL

130 HICKS WAY

AMHERST, MA 01003

E-mail: klement@philos.umass.edu

Webpage: http://people.umass.edu/klement/ 